\title{
REVIEW
}

Open Access

\section{How effective are physical activity interventions when they are scaled-up: a systematic review}

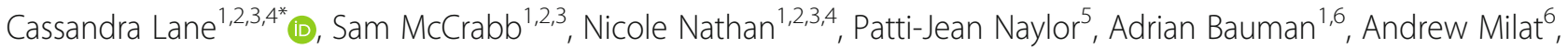
Melanie Lum ${ }^{1,2,3,4}$, Rachel Sutherland ${ }^{1,2,3,4}$, Judith Byaruhanga ${ }^{1,2,3,4}$ and Luke Wolfenden ${ }^{1,2,3,4}$

\begin{abstract}
Background: The 'scale-up' of effective physical activity interventions is required if they are to yield improvements in population health. The purpose of this study was to systematically review the effectiveness of community-based physical activity interventions that have been scaled-up. We also sought to explore differences in the effect size of these interventions compared with prior evaluations of their efficacy in more controlled contexts, and describe adaptations that were made to interventions as part of the scale-up process.

Methods: We performed a search of empirical research using six electronic databases, hand searched reference lists and contacted field experts. An intervention was considered 'scaled-up' if it had been intentionally delivered on a larger scale (to a greater number of participants, new populations, and/or by means of different delivery systems) than a preceding randomised control trial ('pre-scale') in which a significant intervention effect $(p<0.05)$ was reported on any measure of physical activity. Effect size differences between pre-scale and scaled up interventions were quantified ([the effect size reported in the scaled-up study / the effect size reported in the pre-scale-up efficacy trial] $\times 100$ ) to explore any scale-up 'penalties' in intervention effects.

Results: We identified 10 eligible studies. Six scaled-up interventions appeared to achieve significant improvement on at least one measure of physical activity. Six studies included measures of physical activity that were common between pre-scale and scaled-up trials enabling the calculation of an effect size difference (and potential scale-up penalty). Differences in effect size ranged from 132 to $25 \%$ (median $=58.8 \%$ ), suggesting that most scaled-up interventions typically achieve less than $60 \%$ of their pre-scale effect size. A variety of adaptations were made for scale-up - the most common being mode of delivery.

(Continued on next page)
\end{abstract}

\footnotetext{
* Correspondence: Cassandra.lane1@health.nsw.gov.au

'School of Medicine and Public Health, The University of Newcastle, Newcastle, NSW, Australia

${ }^{2}$ Hunter New England Population Health, Hunter New England Area Health Service, Newcastle, NSW, Australia

Full list of author information is available at the end of the article
}

C C The Author(s). 2021 Open Access This article is licensed under a Creative Commons Attribution 4.0 International License, which permits use, sharing, adaptation, distribution and reproduction in any medium or format, as long as you give appropriate credit to the original author(s) and the source, provide a link to the Creative Commons licence, and indicate if changes were made. The images or other third party material in this article are included in the article's Creative Commons licence, unless indicated otherwise in a credit line to the material. If material is not included in the article's Creative Commons licence and your intended use is not permitted by statutory regulation or exceeds the permitted use, you will need to obtain permission directly from the copyright holder. To view a copy of this licence, visit http://creativecommons.org/licenses/by/4.0/ The Creative Commons Public Domain Dedication waiver (http://creativecommons.org/publicdomain/zero/1.0/) applies to the data made available in this article, unless otherwise stated in a credit line to the data. 


\begin{abstract}
(Continued from previous page)
Conclusion: The majority of interventions remained effective when delivered at-scale however their effects were markedly lower than reported in pre-scale trials. Adaptations of interventions were common and may have impacted on the effectiveness of interventions delivered at scale. These outcomes provide valuable insight for researchers and public health practitioners interested in the design and scale-up of physical activity interventions, and contribute to the growing evidence base for delivering health promotion interventions at-scale.
\end{abstract}

Trial registration: PROSPERO CRD42020144842.

Keywords: Physical activity, Scale-up, Scale-up penalty, Adaptations

\section{Background}

Physical inactivity is a priority public health issue due to its high prevalence and contribution to the burden of disease [1]. Although many interventions have been trialled internationally to increase levels of physical activity, few effective interventions are scaled-up to reach broader populations. Scaling up is a deliberate process of taking health interventions that have been proven effective on a small scale and expanding their reach into real world settings [2-4]. The World Health Organization has identified scaling-up physical activity interventions as a priority, as doing so is required if they are to have a benefit at the population level [2].

The effectiveness of physical activity interventions when delivered at-scale is not yet well understood [4]. Most physical activity interventions are trialled under optimal research conditions often using resources, infrastructure and expertise that are not readily available in community or clinical settings $[5,6]$. If found effective, it is suggested that these interventions be more broadly disseminated to reach a greater proportion of the population who could potentially benefit. However, it has been hypothesised that when delivered at-scale in more real-world contexts, the effects of interventions may attenuate - a phenomenon known as a "scale-up penalty" [7-9] or "voltage drop" [10]. We are not aware of any previous reviews characterising the effects of physical activity interventions that have been scaled-up. However, reviews examining the scale-up of other interventions indicate that an interventions' effect size at scale-up is generally lower than that reported in pre-scale evaluations, suggesting that scale-up penalties are common [7, 9]. For example, a review of scaled-up developmental preventive interventions with criminal outcomes found that the effects of scaled-up interventions were typically $50-60 \%$ ( median $=55 \%$ ) lower [9] than the corresponding prescale trial. Similarly, a review of scaled-up obesity interventions found that the effects of scaled-up interventions were typically $75 \%$ or less (median $=51.3 \%$ ) of the effects reported in pre-scale up efficacy trials [7].

Adaptions to interventions are common in the process of scale-up $[3,11,12]$ and are often necessary to ensure that interventions can be delivered with the resources of agencies responsible for their implementation. They can also assist the successful expansion of evidence-based practice into larger, uncontrolled environments by improving intervention fit within diverse contexts (e.g., different political climate, economic conditions, public interest) [13]. For example, interventions adapted for culture can be more effective [14] and McCrabb and colleagues found that cultural adaptations were made to deliver health interventions to other population groups [7]. Moreover, adaptations may assist to overcome barriers such as competing priorities within health systems, limited capacities of implementing organisations, and shortages of available resources to facilitate the scale-up process [15]. There are many benefits to adaptation processes for delivering interventions at-scale, however these can also have a detrimental impact on the effects of interventions [7-9]. Research is needed to appraise intervention adaptations and their resulting impact on an interventions' scalability [16]. This is important for preparing health interventions for scale-up.

Knowledge of whether an intervention deemed effective may have a meaningful population level impact - and whether any adaptations were made that may have impacted this process - is important information for policy makers needing to make decisions regarding the allocation of resources in fiscally constrained environments. The literature regarding the effects and/or adaptations of scaledup physical activity interventions in community settings has not been subject to a systematic evidence synthesis. We sought to address this evidence gap to contribute to the growing evidence base for delivering health promotion interventions at-scale. Specifically, the objectives of this review were (1) to assess the effects of evidence-based health promotion interventions, delivered in community settings, on measures of physical activity following scale-up; (2) to describe differences in effects of interventions established prior to and following scale-up (scale-up penalty) for comparable measures of physical activity and (3) to describe adaptations made to physical activity interventions occurring as part of the scale-up process.

\section{Methods}

The methods used for this review are based on an existing obesity intervention review by McCrabb and 
colleagues [7] and were developed using guidance from the Cochrane Handbook for Systematic Reviews of Interventions Version 5.1.0 [17]. This review was registered with the international prospective register of systematic reviews (PROSPERO; registration number: CRD42020144842) and conducted as per the Preferred Reporting Items for Systematic Reviews and Meta-Analyses (PRISMA) guidelines.

\section{Search}

We performed a search in July 2019 of six electronic data bases (MEDLINE, EMBASE, PsycINFO, Cochrane Central Register of Controlled Trials [CENTRAL], CINA HL, Education Resources Information Center [ERIC]) using terms from reviews by Milat et al. [18], Reis et al. [13], and Charif et al. [19] relating to scaling-up, physical activity, nutrition, obesity and study design (see Additional file 1). We sought to identify further eligible studies by first reference scanning comprehensive systematic reviews of physical activity interventions and their implementation across a range of settings [20-23] and second, by forward searching via (i) contact with field experts, (ii) contact with authors of interventions included in key systematic reviews, and (iii) email with authors of eligible papers.

\section{Eligibility criteria}

Participants of eligible trials included children, adults and families that have been exposed to a scaled-up health promotion intervention that aimed to improve participants' physical activity. Studies assessing the intervention were eligible if they were one of a pair of reports (a pre-scale trial and a scaled-up study) which fit the following criteria: (A) the pre-scale report was a randomised controlled trial (RCT) with evidence of efficacy (statistical significance of $p<0.05$ ) for at least one trial physical activity outcome measured at the individual level; and (B) the scaled-up study reported on the intentional delivery of the intervention to a greater number of individuals than that of the pre-scale trial. We included interventions that had been vertically scaled (introduced across a whole system at the same time; e.g. a mandated policy or practice) or horizontally scaled (gradually introduced across different sites or groups over time; e.g. phased implementation) [3] to a greater number of participants, new populations, and/or by the means of different delivery systems [24]. For scaled-up studies, we considered studies of any randomised or non-randomised trial design so long as they included at least one measure of physical activity using either objective (e.g., pedometers, accelerometers) or self-reported (e.g., self-reported metabolic equivalent of task [MET]) measures. The report pair (pre-scale and scaled-up) did not have to share a common outcome measure, and studies could be focused on any health-related behaviour, such as obesity or nutrition, provided that they reported on a physical activity outcome. Studies were excluded if (i) participant groups were selected on the basis of pre-existing disease or medical condition, (ii) the primary purpose was replication of the intervention, (iii) they were performed in medical/clinical settings, or (iv) the finding of effectiveness at pre-scale was at the sub-group level.

\section{Data screening}

Title, abstract and full text screening occurred independently by two review authors not blinded to the author or journal information. Google translate was used to assess eligibility of abstracts or articles not published in English. Full texts of manuscripts were obtained for all potentially eligible trials for further examination. Decisions regarding inclusion were made between the review author pair and a third reviewer was consulted to resolve any contrariety.

\section{Data extraction and management}

Two review authors independently extracted data and reached consensus for the following: (i) the characteristics of included studies, such as the country and year of publication, sample, study design, trials measures, and outcomes; (ii) the translation stage of each intervention, categorised using the pathways to scaling-up public health interventions described by Indig et al. [25] (efficacy, effectiveness, implementation, or dissemination); (iii) the nature of any adaptations made for scale-up as characterised using a modified Adaptome model [26]; (iv) information to enable assessment of study quality; and (v) any measures of physical activity reported in a standardised way across both trials (objective and/or subjective measurements).

\section{Data synthesis}

The study characteristics and key findings for measures of physical activity of scaled-up studies are described in Additional file 3. Authors of included studies were emailed where questions of study design, methods, intervention adaptations and/or physical activity outcomes arose during any step of data synthesis. Physical activity outcomes were defined using the inventory of physical activity measures provided by Sylvia and colleagues [27].

We synthesised data in relation to the specific study objectives. First, given the heterogeneity among included studies, we narratively synthesised the effects of interventions on measures of physical activity reported in the included scaled-up studies. Second, we assessed differences in effect size from pre-scale trials to scaled-up studies using the extracted measures reported in a standardised way across both reports. Where a standardised measure was not directly conveyed in each, we sought to 
calculate a standardised measure for comparison if sufficient data were provided. For example, the physical activity outcome of MET-minutes per week were reported differently across one evaluation pair: the intervention effect was expressed as a regression coefficient in the pre-scale trial [28] and a between-group difference in the scaled-up study [29]. We were able to calculate the between-group difference for the pre-scale trial using the reported pre- and post-intervention MET-minutes per week for intervention and control groups. Thus, we computed a standardised measure for comparison where it was not originally available.

To assess any scale-up penalty, differences in effect size were quantified using the following formula: effect size reported in the scaled-up study divided by the effect size reported in the pre-scale trial and then multiplied by 100 . A calculation of $100 \%$ indicated that the intervention tested in the scaled-up study had an effect equal to that achieved in the pre-scale trial; values $>100 \%$ indicated that the intervention tested in the scaled-up study had a greater effect than it did in the pre-scale trial; and values $<100 \%$ indicated that a proportion of the intervention effect was retained following scale-up (a scale-up penalty had occurred). Specific scale-up penalties may be inferred by subtracting the proportion of the intervention effect retained from 100. For example, 25\% denoted that the intervention tested in the scaled-up study retained a quarter of the intervention effect following scale-up and had consequently suffered a scale-up penalty of $75 \%$.

Third, we narratively recorded any adaptations made to the intervention based on manuscripts reporting on the pre-scale trial and subsequent scaled-up study. We then searched Google and Google Scholar to identify supplementary material, such as additional studies or published protocols, for additional information where descriptions of interventions within manuscripts were limited, incomplete or unclear.

Adaptations were classified according to the Adaptome model [26] as:

(a) Service setting adaptations - adaptations to elements of the environment where the intervention delivery takes place, such as the physical location and/or the facilitator.

(b) Target audience adaptations - adaptations to the population of interest and/or the 'fit' for the population of interest, such as expanding eligibility criteria to include students of different grades.

(c) Mode of delivery adaptations - adaptations to the channel used to deliver the intervention, such as changed frequency of sessions and/or delivering the session in-person versus via the internet. (d) Cultural adaptations - adaptions to improve cultural appropriateness of an intervention, such as translating resources into other languages used by populations of interest.

(e) Other - adaptations that do not fall into the prior categories, such as the addition of a marketing scheme and/or reducing the monetary value of provided resources.

\section{Results}

Figure 1 displays a PRISMA diagram for this systematic review. The search of databases and additional records identified 5441 titles to screen for eligibility. We contacted corresponding authors of 301 potentially eligible trials, and eight key stakeholders from relevant international organisations. An initial 18 pairs of studies were identified as eligible, six of which were excluded at data extraction for various reasons: the RT for TEENS intervention [30] had been scaled up from an efficacy trial with a statistically significant effect for muscular fitness only, and not for measures of physical activity [31]; the replicated efficacy trial of the $\mathrm{CATCH}$ program in Texas was quasi-experimental [32] and there were no evaluations following the original efficacy trial [33] that reported on the intervention with an expanded reach; the pre-scale trial associated with both FUN5! [34] and SPARK [35] were quasi-experimental (one school was purposefully assigned to the control group to account for attrition issues) [35]; the original pre-scale trial of EPODE was a non-RCT design [36]; and it was unclear whether randomisation had been used in the efficacy trial of Exercise Your Options [37]. The Healthy School Start study [38] was excluded after data extraction as the finding of effectiveness in the pre-scale efficacy trial was the result of sub-group analysis [39]. We included a total of 10 scaled-up interventions for review. Table 1 lists the initial interventions tested for efficacy in the pre-scale RCTs and the corresponding scaled-up intervention. Additional file 2 provides an overview of the quality of evidence (internal validity of each study) as assessed using Cochrane's Risk of Bias tool described in the Cochrane Handbook for Systematic Reviews of Interventions [17].

\section{Characteristics of included studies}

Additional file 3 provides characteristics of the 10 scaled-up studies included in this review. Three trials focused exclusively on physical activity improvements and the remaining seven trials included physical activity as part of a broader health promotion program for either obesity prevention or a general healthy lifestyle.

Four studies were conducted in Australia [46, 48, 50, 53]; two in the United States [44, 55]; one each from Canada [41, 42], the United Kingdom [51], and China [57]; and the 


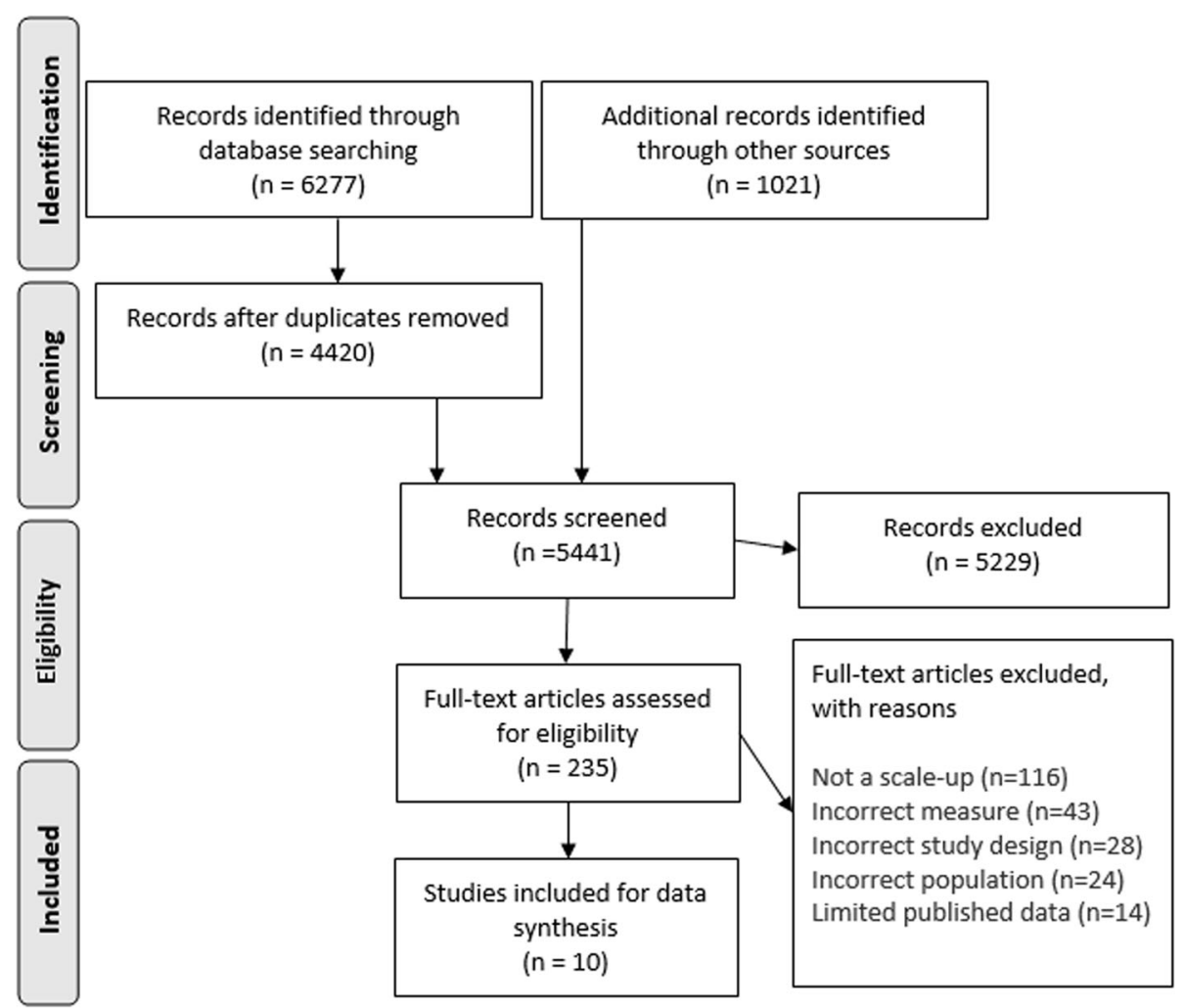

Fig. 1 PRISMA (Preferred Reporting Items for Systematic Review and Meta-Analyses) diagram of included studies

remaining study was conducted across multiple countries (Netherlands, Norway, Portugal, and the United Kingdom) [29].

Target populations of the scaled-up studies varied; two focused on parent-child dyads [46] (one with fathers only [48]); three on primary school students from a variety of grades (grades 3-7) [41, 42, 53, 57]; two on women only ( 40 years or older [55] and 18-50 years of

Table 1 List of included scaled-up interventions and the corresponding pre-scale efficacy trial intervention

\begin{tabular}{ll}
$\begin{array}{l}\text { Pre-scale intervention } \\
\text { name }\end{array}$ & $\begin{array}{l}\text { Scaled-up intervention name } \\
\text { (population, focus) }\end{array}$ \\
\hline AS! BC [40] & AS! BC (children, physical activity) [41, 42] \\
CHAMPS II [43] & CHAMPS III (older adults, physical activity) [44] \\
FFIT [28] & $\begin{array}{l}\text { EuroFIT (men, lifestyle) [29] } \\
\text { MEND [45] }\end{array}$ \\
HDHK [47] & HDHK (children, obesity) [48] \\
HeLP-her [49] & HeLP-her (women, weight) [50] \\
MEND [45] & MEND 7-13 (children, obesity) [51] \\
SCORES [52] & SCORES (children, physical activity) [53] \\
Strong Women-Healthy & Strong Women-Healthy Hearts (women, \\
Hearts [54] & lifestyle) [55] \\
CLICK-obesity [56] & YOG-Obesity (children, lifestyle) [57] \\
\hline
\end{tabular}

age [50]), one on men only (30-65 years of age) [29], and the last on older adults ( 65 years or older) [44].

Four scaled-up studies used a cluster RCT design [41, $42,50,53,57]$, two used a RCT with participants randomised at the individual level $[29,48]$, three used a preand-post, non-controlled design [44, 46, 55], and one study used an intervention evaluation [51]. Of the scaled-up intervention studies, eight were classified as dissemination efforts [41, 42, 44, 46, 48, 51, 53, 55, 57], and two as effectiveness $[29,50]$.

\section{The effectiveness of scaled-up interventions in improving physical activity}

Overall, the majority of interventions (6/10) significantly improved at least one measure of physical activity when scaled-up [29, 46, 48, 53, 55, 57]. Four of these findings were from controlled trials randomised at the individual or cluster level. Compared to controls, objectively assessed steps-per-day significantly increased by both children and fathers in the HDHK RCT [48] as well as participants in the EuroFIT RCT [29]. The SCORES cluster RCT [53] showed no significant intervention effect on the primary outcome of students' total daily minutes of moderate vigorous physical activity (MVPA), however improvements were found with other measures of student physical activity including overall daily 
vigorous activity, school-day MVPA and school-day vigorous activity. The YOG-Obesity cluster RCT [57] also found an intervention effect for students' subjectively assessed MVPA. Differently, no significant improvements were found in the HeLP-her cluster RCT [50] for women's self-reported physical activity (Additional file 3 ).

The other two scaled-up evaluations that found improvements in physical activity used pre- and post- evaluations. Following the intervention, children in Go4Fun [46] increased the number of days/week they spent in $\geq 1 \mathrm{~h}$ of physical activity and improved their cardiovascular fitness levels while women in StrongWomen-Healthy Hearts [55] increased their mean MET-minutes per week (Additional file 3). Differently, self-reported levels of physical activity by participants in CHAMPS [44] did not significantly improve from pre- to post-intervention (Additional file 3).

The physical activity impacts of the remaining two scaled-up evaluations included in this review are unknown: AS! BC [41, 42] reported on intermediate measures of physical activity (teachers delivered minutes of physical activity) not on the direct physical activity outcomes of participants [41, 42], and MEND 7-13 focused on BMI and omitted measures of physical activity [51] (Additional file 3).

\section{The effect size difference from pre-scale to scaled-up (scale-up penalty)}

Seven studies included at least one standardised measure of physical activity - or sufficient data for our review team to calculate a standardised measure - in both the pre-scale efficacy trial and scaled-up study. The first two columns of Table 2 displays the measures of physical activity common to both reports and column three reports the corresponding proportion of the efficacy trial effect size achieved in the scaled-up trial.

Differences in effect size (i.e., the proportion of efficacy) from pre-scale to scaled-up trials varied. Six trial pairs provided a total of nine comparable measures of physical activity, with differences in effect ranging from 132 to $25 \%$ (median $=58.8 \%$; Table 2). Two measures from separate RCTs reported larger effect sizes at follow-up: EuroFIT [29] retained 105.9\% of men's total MET-min/week and HDHK [48] retained 132.3\% of

Table 2 Effect size difference calculated using measures of physical activity common to both pre-scale trial and scaled-up study

\begin{tabular}{|c|c|c|c|}
\hline & Pre-Scale RCT & Scaled-up Study & $\begin{array}{l}\text { Proportion (\%) of } \\
\text { the Efficacy Trial } \\
\text { Effect Size Achieved } \\
\text { in the Scaled-up Study }\end{array}$ \\
\hline CHAMPS & $\begin{array}{l}\text { RCT } \\
\text { Change in intervention group at } 12 \text { month follow-up } \\
\text { Weekly caloric expenditure in PA (kcal/week) } \\
+687, P<.001\end{array}$ & $\begin{array}{l}\text { Pre-post non controlled design } \\
\text { Change in intervention group at } 6 \text { month follow-up } \\
\text { Weekly caloric expenditure in PA (kcal/week) } \\
+213, P=0.10\end{array}$ & 31.0 \\
\hline EuroFIT & $\begin{array}{l}\text { RCT } \\
\text { Adjusted b/n group difference at } 12 \text { weeks and } \\
12 \text { months follow-up } \\
\text { Total MET-min/week } \\
12 \text { weeks: } 1485 \\
12 \text { months: } 844\end{array}$ & $\begin{array}{l}\text { RCT } \\
\text { Adjusted } b / n \text { group difference at } 12 \text { weeks and } \\
12 \text { months follow-up } \\
\text { Total MET-min } / \text { week } \\
12 \text { weeks: } 1020, P<0.001 \\
12 \text { months: } 894, P<0.001\end{array}$ & $\begin{array}{l}68.7 \\
105.9\end{array}$ \\
\hline Go4Fun & $\begin{array}{l}\text { RCT } \\
\text { Within-subjects change at } 6 \text { month follow-up } \\
\text { Recovery heart rate (beats min-1) } \\
-17.9, P<0.0001\end{array}$ & $\begin{array}{l}\text { Pre-post non controlled design } \\
\text { Within-subjects change post-intervention } \\
\text { (10-week follow-up) } \\
\text { Recovery heart rate (beats } \mathbf{m i n}-\mathbf{1} \text { ) } \\
-4.64, P=0.002\end{array}$ & 25.9 \\
\hline $\mathrm{HDHK}$ & $\begin{array}{l}\text { RCT } \\
\text { Mean difference } b / n \text { groups at } 3 \text { month follow-up } \\
\text { Mean steps per day for fathers } \\
2139 \\
\text { Mean steps per day for children } \\
1228\end{array}$ & $\begin{array}{l}\text { RCT } \\
\text { Mean difference } b / n \text { groups at } 14 \text { weeks } \\
\text { Mean steps per day for fathers } \\
1258, P=0.04 \\
\text { Mean steps per day for children } \\
1625, P=0.01\end{array}$ & $\begin{array}{l}58.8 \\
132.3\end{array}$ \\
\hline HeLP-her & $\begin{array}{l}\text { RCTA } \\
\text { djusted between group difference at } 12 \text { month follow-up } \\
\text { Activity self-management score } \\
0.24, P<0.001\end{array}$ & $\begin{array}{l}\mathrm{RCT} \\
\text { Adjusted between group difference at } \\
12 \text { month follow-up } \\
\text { Activity self-management } \\
\text { score } 0.06\end{array}$ & 25.0 \\
\hline SCORES & $\begin{array}{l}\text { RCT } \\
\text { Adjusted b/n group difference at } 6 \text { month follow-up } \\
\text { Total daily MVPA (minutes) } \\
5.7, P=0.194 \\
\text { Within-school MVPA (minutes) } \\
4.1, P=0.211\end{array}$ & $\begin{array}{l}\text { RCT } \\
\text { Adjusted } b / n \text { group difference at } 6 \text { month follow-up } \\
\text { Total daily MVPA (minutes) } \\
1.96, P=0.48 \\
\text { Within-school MVPA (minutes) } \\
2.90, P=0.05\end{array}$ & $\begin{array}{l}34.4 \\
70.7\end{array}$ \\
\hline
\end{tabular}


children's mean steps per day. Across all six trial pairs however, the effect size on a measure of physical activity was lower, ranging from 29 to $75 \%$ (median $=65.6 \%$ ) of the effect reported in the pre-scale trial and so representing a scale-up penalty.

\section{Adaptations occurring for scale-up}

Table 3 displays the categories of adaptations that were reported as part of the scale-up process for each intervention. The most commonly reported adaptation among interventions was "mode of delivery", with all but one intervention reporting at least one adaptation in this category. An example of an adaption of mode of delivery was the addition of a novel technology worn by participants' in EuroFIT as a means of self-monitoring physical activity [29]. The second most common was "other" (8/ 10) which included any adaptations that did not fall under the Adaptome [26] categories; for example, the equipment packs provided to SCORES intervention schools were cost-reduced by AUD $\$ 820$ each [53] and the AS! BC intervention added a healthy eating component $[41,42]$. The next most common was "service setting" (7/10), for example the HDHK workshops were conducted at local schools as opposed to the University [48]. Within the remaining categories, four of the 10 intervention trials reported relevant adaptations that fell within "target audience" (e.g., the YOG-Obesity program included an additional three grades of students [57]) and three that fell within "cultural" (e.g., CHAMPS III materials were translated into Spanish [44]). A synopsis of each pre-scale intervention and details of adaptations made for the subsequent scaled-up variation is provided in Additional file 4.

\section{Discussion}

This review answers important questions to assess the potential public health benefits of physical activity interventions delivered at-scale. We found that interventions identified as efficacious in controlled research conditions often remained so when scaled-up, although they typically are able to achieve a fraction of the effect sizes reported in pre-scale efficacy trials. With the exception of two improved physical activity outcomes, the effects of scaled-up interventions were lower than at pre-scale (median of 58.8\%), suggesting that over half of the effect size might be lost following scale-up. The review also identified that intervention adaptations were common as part of the scale-up process, particularly those made to an interventions' mode of delivery.

Broadly, the findings of this review are consistent with that of other research regarding the effects of interventions when scaled-up and the extent of the scale-up penalty. Systematic reviews of scaled-up preventive criminological interventions (1) and obesity interventions (2) have similarly found that interventions delivered at scale produce statistically significant effects, but that these effects are often heavily discounted relative to pre-scale evaluations - retaining a median effect size of 55 and $51.3 \%$, respectively. While systematic review evidence suggests that any increased bout of physical activity is associated with improved health outcomes [58], reductions in effects at scale are important considerations for health policy makers given the size of investments required to scale-up interventions. This may be particularly the case among physical activity interventions where effect sizes reported among reviews of pre-scale efficacy trials are modest and further reductions in effect may yield marginal benefits to community health [5]. Nonetheless, this review identified two trials in which greater effect sizes were reported at scale. Further understanding of the types of interventions, delivery systems and context in which improvements in effects can be achieved represents an important area for future health research in order to maximise the potential impact of scaling physical activity interventions.

Consistent with the review by McCrabb and colleagues (2), we found that the most frequently reported adaptations were categorised as "mode of delivery". Similarly, a

Table 3 Adaptations made to physical activity interventions for scale-up based on the Adaptome model [26]

\begin{tabular}{|c|c|c|c|c|c|}
\hline & Mode of Delivery & Service Setting & Target Audience & Cultural & Other \\
\hline$A S ! B C$ & $x$ & $x$ & $x$ & & $x$ \\
\hline CHAMPS & $x$ & $x$ & & $x$ & \\
\hline EurofIT & $x$ & & & $x$ & $x$ \\
\hline Go4Fun & $x$ & $x$ & & $x$ & $x$ \\
\hline HDHK & $x$ & $x$ & & & \\
\hline HeLP-her & $x$ & $x$ & $x$ & & $x$ \\
\hline MEND 7-13 & & & & & $x$ \\
\hline SCORES & $x$ & $x$ & $x$ & & $x$ \\
\hline Strong Women ... & $x$ & $x$ & & & $x$ \\
\hline YOG-Obesity & $x$ & & $x$ & & $x$ \\
\hline
\end{tabular}


2018 systematic review of 42 evidence-based public health interventions from across the globe (3) found that all of the interventions made "content" adaptations that met the definition for "mode of delivery" used in this review. There are numerous delivery modalities available for health interventions, the choice of which varies by factors such as cost, population reach, and fit with the delivery setting [59]. Modes of delivery used within controlled research conditions are often researcher intensive and costly. Such adaptations are likely necessary to make wide scale implementation of these interventions more achievable - that is, to reach a greater proportion of target populations at a reasonable cost $[4,60]$. This might explain the common occurrence of these adaptations for disseminating public health interventions broadly.

Interestingly, some scaled-up reports including EuroFIT [29], HDHK [48], Go4Fun [46] and SCORES [53] explicitly stated that the intervention was designed with the intent to be scaled-up. These interventions tended to report lower penalties than other trials [29, 48, 53]. The development of health interventions with early consideration of scale-up is important [61] and may assist to preserve the effect size. Indeed assessing the effects of interventions using modalities suitable for delivery atscale and under more naturalistic research conditions might provide better insight for policy makers regarding the effects of these interventions when scaled in the real world, and reduce the magnitude of any scale-up penalty. Such 'practice-based evidence' could be generated through quality evaluations undertaken as part of government investments in physical activity program development and delivery. While most government funded health promotion programs are not evaluated [62], innovative and successful models of how researchers can work with and support routine quality pragmatic program evaluations are emerging [63]. There are a number of frameworks [2, 3, 64] and scalability assessment tools (4) available to assist with the design and scale-up of health interventions to support this work. Furthermore, the Pragmatic Explanatory Continuum Indicator Summary Tool (PRECIS-2) [65] describes a range of pragmatic research trial design characteristics that may enhance the applicability of research findings to real world contexts and was designed to help match research design decisions to how the trial results are intended to be used. The more widespread application of such tools in the conduct of physical activity intervention trials appears warranted to facilitate their scale-up.

A number of limitations of this review are worth considering. We used relatively few search terms relating to scale-up and, despite the support of a robust search strategy, we may have missed potentially eligible studies that used comparable terms such as adoption or diffusion. We did not include those interventions which had been scaled-up without an initial RCT nor those without a report of its intentional delivery on a larger scale since an original efficacy trial. For example, although the $\mathrm{CATCH}$ intervention is a well-known scaled-up physical activity intervention, there were no eligible scaled-up reports available in the literature. More information regarding other scaled-up physical activity interventions that did not meet our eligibility criteria can be found in the 2018 systematic review by Reis and colleagues (6).

The restriction of this review to interventions that had been evaluated pre-scale via randomised trial may have also excluded other interventions that are not amenable to testing via randomised designs, such as those where changes to systems are undertaken as part of the intervention. Similarly, we identified interventions as effective based on findings of statistical significance $(p<0.05)$. Statistical significance, however, is not a measure of the clinical or public health meaningfulness of improvements in physical activity. In light of these limitations, the review may have omitted interventions that may yield meaningful improvements in physical activity, and therefore have considerable scale-up potential. End-users should be mindful of both the size of the effect and the certainty of the estimate when appraising the benefits of physical activity interventions when scaled-up.

A further limitation is the exclusion of intermediate measures of physical activity (i.e., measures that correspond to an increase in physical activity) from data synthesis. For example, an increase in minutes of physical activity delivered by teachers in AS! BC (7). A broader inclusion criteria may have enabled capture of a greater pool of studies and yielded greater insights into the scale-up process.

Every effort was taken to standardize assessments of pre- and post-scale up effects, for example via comparing the same measure, instrument and pre-post or between group comparisons between pre-scale and scaleup evaluations. As such, we anticipated that differences between effects of interventions were likely due to the process of scaling up, be they related to adaptations to the intervention, its implementation, changes to the population groups (e.g., baseline activity levels) or other contextual factors. Such assertions still require further research to establish important effect modifiers. Further, other methodological differences such as seasonal variations in the assessment period, or the methods employed in statistical analyses may contribute to differences in the estimates of effects between pre- and post-scale reports.

Finally, we were unable to quantify the effect size difference (and potential scale-up penalty) for some interventions. Where we were able to perform this calculation, there were some instances in which the study design and/or primary measure used in the scaled- 
up evaluation did not match that of its corresponding pre-scale RCT $[44,46]$. As interventions move through stages of the research process - from efficacy, replication and effectiveness trials to then test dissemination, implementation and scale-up strategies - the need for assessment of their effects on individual physical activity behaviour (particularly assessed in the same way as efficacy trials) becomes less salient, and arguably unnecessary [66, 67]. Nonetheless, the effects of scaled-up interventions which did not include measures of physical activity in this review, and whether a scale-up penalty has been incurred, remains unknown. The science of scale-up is a nascent field of research; as the evidence base grows so will the opportunity to address several of these limitations.

\section{Conclusions}

Effective public health interventions, including those with an impact on physical activity levels, must be scaled-up to achieve population-wide health improvements [3, 4, 13, 25, 60, 64]. While even small improvements in physical activity can have a positive health impact, the effects of physical activity interventions are typically much smaller than reported in pre-scale efficacy trials. Appraising the extent to which reductions in effect may occur will be important for policy makers and practitioners to assess the likely population health benefits of investment in scale-up.

\section{Supplementary Information}

The online version contains supplementary material available at https://doi. org/10.1186/s12966-021-01080-4.

\section{Additional file 1. \\ Additional file 2 . \\ Additional file 3. \\ Additional file 4. \\ Additional file 5.}

\section{Abbreviations}

PRISMA: Preferred Reporting Items for Systematic Reviews and Meta-analysis; $\mathrm{RCT}$ : randomised controlled trial; MET: metabolic equivalent of task; MVPA: moderate vigorous physical activity

\section{Acknowledgements}

Not applicable.

\section{Authors' contributions}

LW conceived and designed the study. LW and SM developed the search strategy and SM conducted the search. CL, ML and JB screened studies for inclusion with LW acting as third reviewer for all stages. CL and SM extracted data with $M L$ acting as a third reviewer. $M L$ and $J B$ analysed studies for RoB. $C L$ and $S M$ synthesized all data with $L W$ and NN acting as third reviewers. $C L, S M, L W, N N, P N, A B$ and $A M$ interpreted results. $C L$ drafted the manuscript with all co-authors contributing to drafts of the paper. All authors approved the final manuscript.

\section{Funding}

This study was funded by a NSW Cancer Council Program Grant. They had no input into the design of the study; the collection, analysis, and interpretation of data; nor in writing the manuscript.

Availability of data and materials

The datasets used for the current study are available from the corresponding author on reasonable request.

Ethics approval and consent to participate

Not applicable.

Consent for publication

Not applicable.

\section{Competing interests}

The authors declare that they have no competing interests.

\section{Author details}

${ }^{1}$ School of Medicine and Public Health, The University of Newcastle, Newcastle, NSW, Australia. ${ }^{2}$ Hunter New England Population Health, Hunter New England Area Health Service, Newcastle, NSW, Australia. ${ }^{3}$ Priority Research Centre for Health Behaviour, The University of Newcastle, Newcastle, NSW, Australia. ${ }^{4}$ Hunter Medical Research Institute, New Lambton Heights, NSW, Australia. ${ }^{5}$ School of Exercise Science, Physical and Health Education, University of Victoria, Victoria, BC, Canada. ${ }^{6}$ School of Public Health, University of Sydney, Sydney, NSW, Australia.

Received: 25 June 2020 Accepted: 5 January 2021

Published online: 22 January 2021

\section{References}

1. Kohl HW III, Craig CL, Lambert EV, Inoue S, Alkandari JR, Leetongin G, et al. The pandemic of physical inactivity: global action for public health. Lancet. 2012;380(9838):294-305.

2. World Health Organization. Practical guidance for scaling up health service innovations. Geneva: World Health Organization; 2009.

3. Milat AJ, Newson R, King L, Rissel C, Wolfenden L, Bauman A, et al. A guide to scaling up population health interventions. Public Health Res Pract. 2016; 26(1):e2611604.

4. Milat AJ, King L, Bauman AE, Redman S. The concept of scalability: increasing the scale and potential adoption of health promotion interventions into policy and practice. Health Promot Int. 2012;28(3):285-98.

5. Finch $M$, Jones J, Yoong S, Wiggers J, Wolfenden L. Effectiveness of Centrebased childcare interventions in increasing child physical activity: a systematic review and meta-analysis for policymakers and practitioners. Obes Rev. 2016:17(5):412-28.

6. Yoong SL, Wolfenden L, Clinton-Mcharg T, Waters E, Pettman TL, Steele E, et al. Exploring the pragmatic and explanatory study design on outcomes of systematic reviews of public health interventions: a case study on obesity prevention trials. J Public Health. 2014;36(1):170-6.

7. McCrabb S, Lane C, Hall A, Milat A, Bauman A, Sutherland R, et al. Scalingup evidence-based obesity interventions: a systematic review assessing intervention adaptations and effectiveness and quantifying the scale-up penalty. Obes Rev. 2019;20(7):1-19.

8. Tommeraas T, Ogden T. Is there a scale-up penalty? Testing behavioral change in the scaling up of parent management training in Norway. Adm Policy Ment Health Ment Health Serv Res. 2017:44(2):203-16.

9. Yohros A, Welsh BC. Understanding and quantifying the scale-up penalty: a systematic review of early developmental preventive interventions with criminological outcomes. J Dev Life Course Criminol. 2019;5:481-97.

10. Kilbourne AM, Neumann MS, Pincus HA, Bauer MS, Stall R. Implementing evidence-based interventions in health care: application of the replicating effective programs framework. Implement Sci. 2007;2(1):42.

11. Baumann A, Cabassa LJ, Stirman SW. Adaptation in dissemination and implementation science. In: Dissemination and implementation research in health: translating science to practice, vol. 2; 2017. p. 286-300.

12. Gray SM, McKay HA, Hoy CL, Lau E, Ahn R, Lusina-Furst S, et al. Getting ready for scale-up of an effective older adult physical activity program: characterizing the adaptation process. Prev Sci. 2020;21(3):355-65. 
13. Reis RS, Salvo D, Ogilvie D, Lambert EV, Goenka S, Brownson RC, et al. Scaling up physical activity interventions worldwide: stepping up to larger and smarter approaches to get people moving. Lancet. 2016;388(10051): 1337-48.

14. Barrera M Jr, Castro FG, Strycker LA, Toobert DJ. Cultural adaptations of behavioral health interventions: a progress report. J Consult Clin Psychol. 2013;81(2):196

15. World Health Organization. Nine steps for developing a scaling-up strategy. 2010.

16. Milat A, Lee K, Conte K, Grunseit A, Wolfenden L, Van Nassau F, et al. Intervention Scalability Assessment Tool: A decision support tool for health policy makers and implementers. Health Res Policy Syst. 2020;18(1):1-17.

17. Higgins JPT, Green S, eds. Cochrane handbook for systematic reviews of interventions version 5.1.0 [updated March 2011]. The Cochrane Collaboration, 2011. www.cochrane-handbook.org.

18. Milat AJ, Bauman A, Redman S. Narrative review of models and success factors for scaling up public health interventions. Implement Sci. 2015;10(1): 113.

19. Charif AB, Zomahoun HTV, LeBlanc A, Langlois $L$, Wolfenden $L$, Yoong $S L$, et al. Effective strategies for scaling up evidence-based practices in primary care: a systematic review. Implement Sci. 2017;12(1):139.

20. McFadyen T, Chai LK, Wyse R, Kingsland M, Yoong SL, Clinton-Mcharg T, et al. Strategies to improve the implementation of policies, practices or programmes in sporting organisations targeting poor diet, physical inactivity, obesity, risky alcohol use or tobacco use: a systematic review. BMJ Open. 2018;8(9):e019151.

21. Wolfenden L, Goldman S, Stacey FG, Grady A, Kingsland M, Williams CM, et al. Strategies to improve the implementation of workplace-based policies or practices targeting tobacco, alcohol, diet, physical activity and obesity. Cochrane Database Syst Rev. 2018;11:CD012439.

22. Wolfenden L, Nathan NK, Sutherland R, Yoong SL, Hodder RK, Wyse RJ, et al. Strategies for enhancing the implementation of school-based policies or practices targeting risk factors for chronic disease. Cochrane Database Syst Rev. 2017;11:CD011677.

23. Wolfenden L, Barnes C, Jones J, Finch M, Wyse RJ, Kingsland M, et al. Strategies to improve the implementation of healthy eating, physical activity and obesity prevention policies, practices or programmes within childcare services. Cochrane Database Syst Rev. 2020;2:CD011779.

24. Aarons GA, Sklar M, Mustanski B, Benbow N, Brown CH. "Scaling-out" evidence-based interventions to new populations or new health care delivery systems. Implement Sci. 2017;12(1):111.

25. Indig D, Lee K, Grunseit A, Milat A, Bauman A. Pathways for scaling up public health interventions. BMC Public Health. 2018;18(1):68.

26. Chambers DA, Norton WE. The adaptome: advancing the science of intervention adaptation. Am J Prev Med. 2016;51(4):S124-S31.

27. Sylvia LG, Bernstein EE, Hubbard JL, Keating L, Anderson EJ. Practical guide to measuring physical activity. J Acad Nutr Diet. 2014;114(2):199-208.

28. Hunt K, Wyke S, Gray CM, Anderson AS, Brady A, Bunn C, et al. A gendersensitised weight loss and healthy living programme for overweight and obese men delivered by Scottish premier league football clubs (FFIT): a pragmatic randomised controlled trial. Lancet. 2014;383(9924):1211-21.

29. Wyke S, Bunn C, Andersen E, Silva MN, Van Nassau F, McSkimming P, et al. The effect of a programme to improve men's sedentary time and physical activity: the European fans in training (EuroFIT) randomised controlled trial. PLoS Med. 2019;16(2):e1002736.

30. Kennedy SG, Smith JJ, Morgan PJ, Peralta LR, Hilland TA, Eather N, et al. Implementing resistance training in secondary schools: a cluster randomized controlled trial. Med Sci Sports Exerc. 2018;50(1):62-72.

31. Smith JJ, Morgan PJ, Plotnikoff RC, Dally KA, Salmon J, Okely AD, et al. Smart-phone obesity prevention trial for adolescent boys in low-income communities: the ATLAS RCT. Pediatrics. 2014;134(3):e723-e31.

32. Heath EM, Coleman KJ. Adoption and institutionalization of the child and adolescent trial for cardiovascular health (CATCH) in El Paso, Texas. Health Promotion Pract. 2003:4(2):157-64.

33. Luepker RV, Perry CL, McKinlay SM, Nader PR, Parcel GS, Stone EJ, et al. Outcomes of a field trial to improve children's dietary patterns and physical activity: the child and adolescent trial for cardiovascular health (CATCH). Jama. 1996;275(10):768-76.

34. Nigg C, Geller K, Adams P, Hamada M, Hwang P, Chung R. Successful dissemination of fun 5-a physical activity and nutrition program for children. Transl Behav Med. 2012;2(3):276-85.
35. Sallis JF, McKenzie TL, Alcaraz JE, Kolody B, Faucette N, Hovell MF. The effects of a 2-year physical education program (SPARK) on physical activity and fitness in elementary school students. Sports, play and active recreation for kids. Am J Public Health. 1997:87(8):1328-34.

36. Borys J-M, Richard P, Ruault Du Plessis H, Harper P, Levy E. Tackling health inequities and reducing obesity prevalence: the EPODE community-based approach. Ann Nutr Metab. 2016;68(2):35-8.

37. Alston JM, Chalfant JA, James JS. Evaluation of nutrition education by the dairy Council of California. In: The economics of commodity promotion programs: Lessons from California; 2005. p. 287-313.

38. Nyberg G, Norman Å, Sundblom E, Zeebari Z, Elinder LS. Effectiveness of a universal parental support programme to promote health behaviours and prevent overweight and obesity in 6-year-old children in disadvantaged areas, the Healthy School Start Study II, a cluster-randomised controlled trial. Int J Behav Nutr Phys Act. 2016;13(1):1-4.

39. Nyberg G, Sundblom E, Norman $\AA$, Bohman B, Hagberg J, Elinder LS. Effectiveness of a universal parental support Programme to promote healthy dietary habits and physical activity and to prevent overweight and obesity in 6-year-old children: the healthy school start study, a clusterrandomised controlled trial. PLoS One. 2015;10(2):e0116876.

40. Naylor P-J, Macdonald HM, Warburton DE, Reed KE, McKay HA. An active school model to promote physical activity in elementary schools: action schools! BC. Br J Sports Med. 2008;42(5):338-43.

41. McKay HA, Macdonald HM, Nettlefold L, Masse LC, Day M, Naylor P-J. Action schools! BC implementation: from efficacy to effectiveness to scale-up. Br J Sports Med. 2015:49(4):210-8.

42. Mâsse LC, McKay H, Valente M, Brant R, Naylor P-J. Physical activity implementation in schools: a 4-year follow-up. Am J Prev Med. 2012;43(4):369-77.

43. Stewart AL, Verboncoeur CJ, McLellan BY, Gillis DE, Rush S, Mills KM, et al. Physical activity outcomes of CHAMPS II: a physical activity promotion program for older adults. J Gerontol Ser A Biol Med Sci. 2001;56(8):M465M70.

44. Stewart AL, Gillis D, Grossman M, Castrillo M, McLellan B, Sperber N, et al. PEER REVIEWED: Diffusing a Research-based Physical Activity Promotion Program for Seniors Into Diverse Communities: CHAMPS III. Prev Chronic Dis. 2006;3(2):1-16.

45. Sacher PM, Kolotourou M, Chadwick PM, Cole TJ, Lawson MS, Lucas A, et al. Randomized controlled trial of the MEND program: a family-based community intervention for childhood obesity. Obesity. 2010;18(n1s):S62-S8.

46. Hardy LL, Mihrshahi S, Gale J, Nguyen B, Baur LA, O'Hara BJ. Translational research: are community-based child obesity treatment programs scalable? BMC Public Health. 2015;15(1):652.

47. Morgan PJ, Lubans DR, Callister R, Okely AD, Burrows TL, Fletcher R, et al. The 'healthy dads, healthy kids' randomized controlled trial: efficacy of a healthy lifestyle program for overweight fathers and their children. Int J Obes. 2011;35(3):436.

48. Morgan PJ, Collins CE, Plotnikoff RC, Callister R, Burrows T, Fletcher R, et al, The 'healthy dads, healthy kids' community randomized controlled trial: a community-based healthy lifestyle program for fathers and their children. Prev Med. 2014;61:90-9.

49. Lombard C, Deeks A, Jolley D, Ball K, Teede H. A low intensity, community based lifestyle programme to prevent weight gain in women with young children: cluster randomised controlled trial. BMJ. 2010:341(jul13 1):c3215.

50. Lombard C, Harrison C, Kozica S, Zoungas S, Ranasinha S, Teede H. Preventing weight gain in women in rural communities: a cluster randomised controlled trial. PLoS Med. 2016;13(1):e1001941.

51. Fagg J, Chadwick P, Cole TJ, Cummins S, Goldstein H, Lewis H, et al. From trial to population: a study of a family-based community intervention for childhood overweight implemented at scale. Int J Obes. 2014;38(10):1343-9.

52. Cohen KE, Morgan PJ, Plotnikoff RC, Callister R, Lubans DR. Physical activity and skills intervention: SCORES cluster randomized controlled trial. Med Sci Sports Exerc. 2015;47(4):765-74.

53. Sutherland RL, Nathan NK, Lubans DR, Cohen K, Davies LJ, Desmet C, et al. An RCT to facilitate implementation of school practices known to increase physical activity. Am J Prev Med. 2017;53(6):818-28.

54. Folta SC, Lichtenstein AH, Seguin RA, Goldberg JP, Kuder JF, Nelson ME. The StrongWomen-healthy hearts program: reducing cardiovascular disease risk factors in rural sedentary, overweight, and obese midlife and older women. Am J Public Health. 2009;99(7):1271-7.

55. Folta SC, Seguin RA, Chui KKH, Clark V, Corbin MA, Goldberg JP, et al. National Dissemination of StrongWomen-healthy hearts: a community- 
based program to reduce risk of cardiovascular disease among midlife and older women. Am J Public Health. 2015;105(12):2578-85.

56. Xu F, Ware RS, Leslie E, Tse LA, Wang Z, Li J, et al. Effectiveness of a randomized controlled lifestyle intervention to prevent obesity among Chinese primary school students: CLICK-obesity study. PLoS One. 2015; 10(10):e0141421.

57. Wang Z, Xu F, Ye Q, Tse L, Xue H, Tan Z, et al. Childhood obesity prevention through a community-based cluster randomized controlled physical activity intervention among schools in China: the health legacy project of the 2nd world summer youth olympic games (YOG-obesity study). Int J Obes. 2018; 42(4):625.

58. Jakicic JM, Kraus WE, Powell KE, Campbell WW, Janz KF, Troiano RP, et al. Association between bout duration of physical activity and health: systematic review. Med Sci Sports Exerc. 2019;51 (6):1213-9.

59. Beall RF, Baskerville N, Golfam M, Saeed S, Little J. Modes of delivery in preventive intervention studies: a rapid review. Eur J Clin Investig. 2014; 44(7):688-96.

60. Milat AJ, King L, Newson R, Wolfenden L, Rissel C, Bauman A, et al. Increasing the scale and adoption of population health interventions: experiences and perspectives of policy makers, practitioners, and researchers. Health Res Policy Syst. 2014;12(1):18.

61. World Health Organization \& ExpandNet. Beginning with the end in mind: planning pilot projects and other programmatic research for successful scaling up. 2011.

62. Milat AJ, Bauman AE, Redman S, Curac N. Public health research outputs from efficacy to dissemination: a bibliometric analysis. BMC Public Health. 2011;11(1):934.

63. Wolfenden L, Yoong SL, Williams CM, Grimshaw J, Durrheim DN, Gillham K, et al. Embedding researchers in health service organizations improves research translation and health service performance: the Australian hunter New England population health example. J Clin Epidemiol. 2017;85:3.

64. Barker PM, Reid A, Schall MW. A framework for scaling up health interventions: lessons from large-scale improvement initiatives in Africa. Implement Sci. 2015;11(1):12.

65. Loudon K, Treweek S, Sullivan F, Donnan P, Thorpe KE, Zwarenstein M. The PRECIS-2 tool: designing trials that are fit for purpose. BMJ. 2015;350:h2147.

66. Bauman A, Nutbeam D. Evaluation in a nutshell: a practical guide to the evaluation of health promotion programs. AU: McGraw-Hill Education / Australia; 2013. ISBN: $9780071016209 ;$ ISBN-10: 0071016201.

67. Curran GM, Bauer M, Mittman B, Pyne JM, Stetler C. Effectivenessimplementation hybrid designs. Med Care. 2012;50(3):217-26.

\section{Publisher's Note}

Springer Nature remains neutral with regard to jurisdictional claims in published maps and institutional affiliations.

Ready to submit your research? Choose BMC and benefit from:

- fast, convenient online submission

- thorough peer review by experienced researchers in your field

- rapid publication on acceptance

- support for research data, including large and complex data types

- gold Open Access which fosters wider collaboration and increased citations

- maximum visibility for your research: over $100 \mathrm{M}$ website views per year

At $\mathrm{BMC}$, research is always in progress.

Learn more biomedcentral.com/submissions 